\title{
Trans-oral, Carbon Dioxide-Assisted Excision of an Unusual Schwannoma of the Tongue Base: Case Report and Review of the Literature
}

\author{
Zakaria Raee Soliman ${ }^{1}$ Mohammad Kamal Mobashir ${ }^{2}$ Sherif Mohammad Askar ${ }^{30}$ \\ 1 Oto-Rhino-Laryngology-Head and Neck (ORL-HN) Surgery, Military \\ Medical Academy Ringgold Standard Institution, Cairo, Egypt \\ Address for correspondence Sherif Mohammad Askar, ORL-HN \\ 2 ORL-HN Surgery, Faculty of Medicine, Zagazig University, Zagazig, \\ Surgery, Zagazig University, Sharkia Governorate, Egypt, \\ Zagazig 44519, Egypt (e-mail: askr_sh@yahoo.com). \\ Egypt \\ ${ }^{3}$ ORL-HN Surgery, Zagazig University, Zagazig, Egypt
}

Int Arch Otorhinolaryngol 2019;23:e354-e359.

\begin{abstract}
Introduction Schwannomas are benign, solitary, encapsulated tumors that may originate at any site of the peripheral nervous system, with the exception of the olfactory and optic nerves. Schwannomas of the base of tongue are very rare, and only sporadic cases are documented. The tongue base represents a challenge for surgeons. Carbon dioxide $\left(\mathrm{CO}_{2}\right)$ laser might provide an effective surgical option for such lesions because of the easy access to the lesion, the bloodless surgical field and optimum epithelization of wounds.

Objective We present an unusual case of pedunculated schwannoma of the tongue base treated via transoral $\mathrm{CO}_{2}$-assisted excision. We also provide a review of the available literature, in English language, on humans.

Data synthesis The authors searched the PubMed database and Google up to July 2018. The following search terms were applied: tongue and lingual, combined with schwannoma and neurilemmoma. Titles and abstracts were screened, and, then, only supraglottic (hypopharyngeal) tongue base masses were considered. Fourteen articles were included in this review, reporting 17 cases. The age of the patients ranged from 9 to 39 years, affecting predominantly females. Dysphagia and lump sensations were the most common

Keywords

- carbon dioxide laser

- tongue base schwannoma

- deglutition disorders

- deglutition presenting symptoms, and the mean follow-up period range was 1.5 to 60 months (mean $=13$ months). There was no evidence of recurrence in any of the cases.

Conclusion We could conclude that tongue base schwannomas are rare. Transoral complete excision of the tumor is the treatment of choice. $\mathrm{CO}_{2}$ laser surgery is a minimally invasive treatment option that has been performed in few reports with no recurrence and with favorable outcomes.
\end{abstract}

\section{Introduction}

Schwannomas were first described by Verocay in 1910. They are benign, solitary, encapsulated tumors that may originate (1DSherif Mohammad Askar's ORCID is https://orcid.org/0000-0003-
0240-7106.

received

October 6, 2018

accepted

May 8, 2019

10.1055/s-0039-1692404. ISSN $1809-9777$. at any site of the peripheral nervous system, with the exception of the olfactory and optic nerves. Approximately 25 to $40 \%$ of schwannomas arise in the head and neck region, which makes this the most frequent location of this entity $;^{1-3}$ however, only $1 \%$ of these might occur intraorally. While pharyngeal schwannomas are rare, schwannomas at

Copyright @ 2019 by Thieme Revinter

Publicações Ltda, Rio de Janeiro, Brazil

License terms

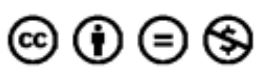


the base of the tongue (BT) are very rare, and only sporadic cases have been documented. The goal of the treatment of such tumors is complete excision, which results in very low rates of recurrence. ${ }^{4-25}$ The BT represents a challenge for surgeons regarding operative complications, difficult approach and postoperative functional disabilities. With this kind of surgery, open approaches have sometimes been described for excision of large lesions. Several disadvantages and hazards have been reported. ${ }^{13,16,25-29}$ Excision of these benign masses requires skillful, precise and minimal tissue dissection, which can be accomplished by $\mathrm{CO}_{2}$ laser (especially when coupled with a surgical microscope). In this way, $\mathrm{CO}_{2}$ laser might provide an effective surgical option for such lesions because of the easy access to the lesion, the bloodless surgical field and optimum epithelization of wounds. ${ }^{26}$

In this work, we present an unusual case of pedunculated schwannoma of the BT at the hypopharyngeal/supraglottic area (treated via transoral $\mathrm{CO}_{2}$-assisted excision) and provide a review of the available literature in English language. We could hypothesize that transoral $\mathrm{CO}_{2}$ laser intervention should be added to the surgical armamentarium for the management of future similar cases in such a challenging area.

\section{Case Report and Review of Literature}

\section{Case Report}

This study was conducted according to the declaration of Helsinki on Biomedical Research Involving Human Subjects, and a written consent was obtained from the patient. The protocol of the investigation was approved by the Institutional Review Board (2593). A 40-year-old female patient was referred to the Oto-Rhino-Laryngology-Head and Neck surgery department with a history of over 5 years of foreign body sensation in the throat, mild respiratory obstructive symptoms, and gradually progressive difficulty in deglutition. No medical history or medications of importance were reported. She had no fever, no blood in her saliva, and her general condition was good. Upon oral examination, a smooth, lobulated, large pedunculated mass was detected behind the tongue, with intact surface mucosa and moves up on gaging. Otherwise, her oral examination was unremarkable and there were no clinical cervical lymph node enlargements or neurological deficits. She had no coexisting systemic illnesses. The patient's hematological and urine investigations were normal. The computed tomography (CT) showed a large $(3.6 \times 3.5 \mathrm{~cm})$ left-side BT mass with no radiological criteria of malignancy (-Figs. 1, 2)

Complete excision of the mass was performed under general anesthesia (with the patient in tonsillectomy position) using a Sharplan $1055 \mathrm{~S} \mathrm{CO}_{2}$ laser (Sharplan Lasers LTD, London, United Kingdom) at a continuous super-pulsed mode, focused beam, 5 to 9 Watts and $0.5 \mathrm{~mm}$ spot size; wavelength of 10,600 $\mathrm{nm}$. The laser was coupled with a Carl Zeiss S21-OPMI 111 surgical microscope (Carl Zeiss AG, Oberkochen, Germany), with 300 to $400 \mathrm{~mm}$ objective lenses

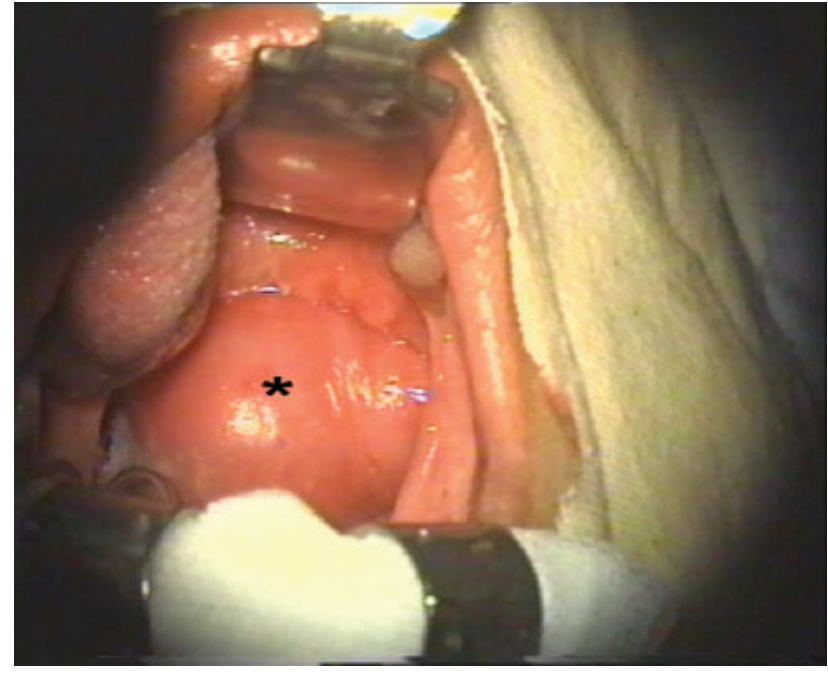

Fig. 1 Base of tongue schwannoma intraoperative view; ( ${ }^{*}$ ) asterisk on the lesion.

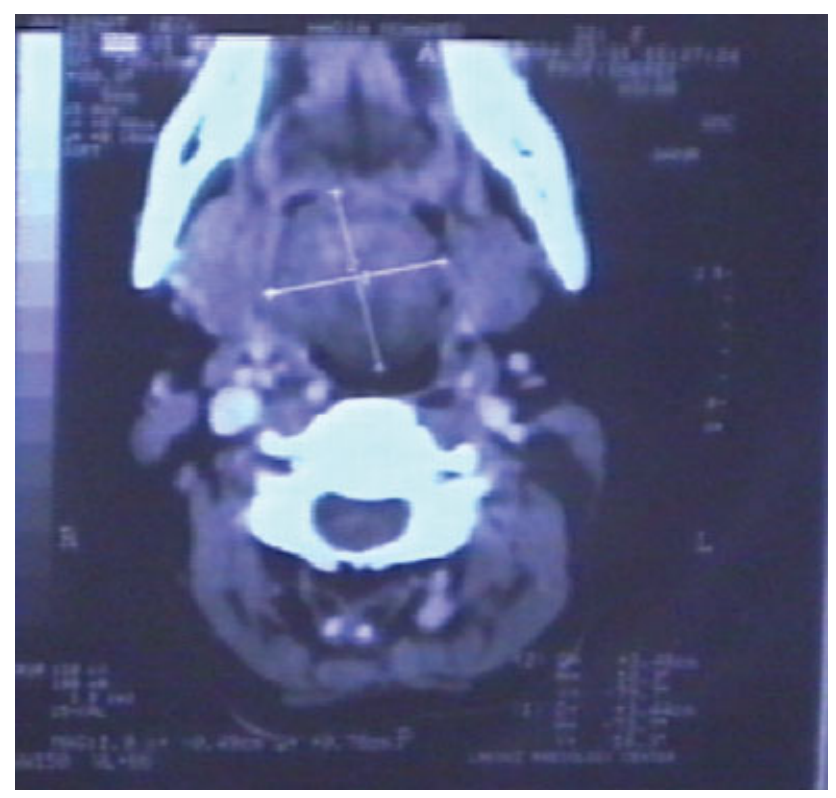

Fig. 2 Base of tongue schwannoma preoperative computed tomography.

connected to a DX pal-202320 20 Storz telecam video camera (Karl Storz SE \& Co. KG, Tuttlingen, Germany) with a micromanipulator. The patient's face was protected with a large wet gauze cover, and the operative field (mouth and pharynx) was covered with wet gauze. A 50-ml syringe loaded with saline was kept ready to deal with any endotracheal tube fires. The swelling was well encapsulated and had a good cleavage plane (-Fig. 2). Dissection proceeded strictly on the capsule, in the plane of cleavage, avoiding hazardous effects on the neurovascular structures at the BT, especially the lingual nerve. The mass was dissected anteriorly, where the hyoid bone was exposed. The excised mass had a smooth surface, well-defined round borders, and was greyish-white in color. No significant bleeding was encountered, and 


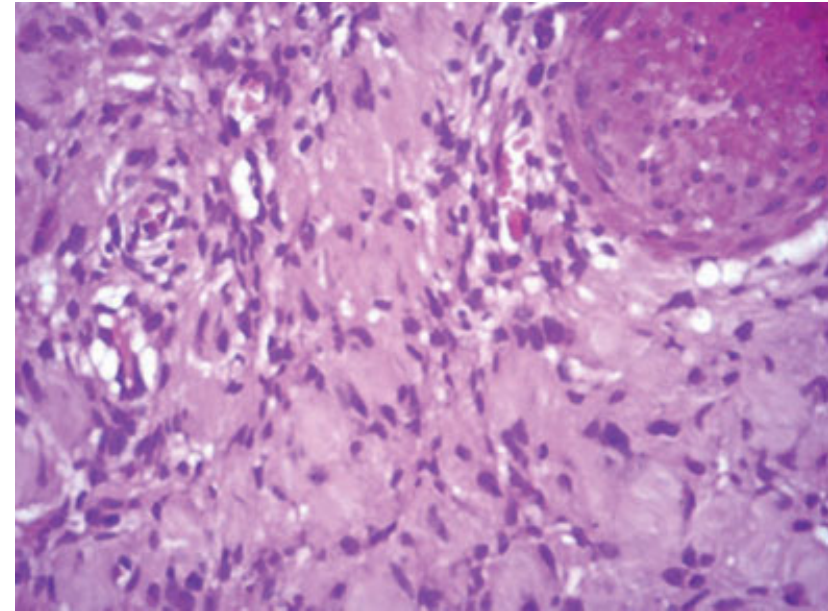

Fig. 3 Base of tongue schwannoma showing the palisading arrangement of the nuclei of the spindle-shaped cells (hematoxylin \& eosin $x 400)$

hemostasis was accomplished through a defocused laser beam or electrodiathermy. At the end of the surgery, the edges and depth of the wound were usually kept smooth and at the same level, as much as possible, to guarantee rapid and optimal reepithelization. After complete excision, an approximation suture was undertaken between the epiglottis and the BT to stabilize the epiglottis and prevent it from falling backwards. Postoperative antibiotics were not prescribed, and only oral paracetamol tablets ( $500 \mathrm{mg}$ every 12 hours for 3 days) were enough for pain control. The postoperative course was smooth, with good wound healing, and deglutition disorders were improved.

Excised tissues were sent for histopathological examination; grossly, the mass was mucous membrane-covered, pale, well-encapsulated, measuring about $3.5 \mathrm{~cm}$ in diameter, and had a firm gray-white glistening cut surface. Microscopic examination confirmed clear margins. The tumor was composed of spindle cells with long, twisted, and wavy nuclei and abundant, pale eosinophilic cytoplasm. The cellular arrangement showed two different patterns: a hypercellular pattern

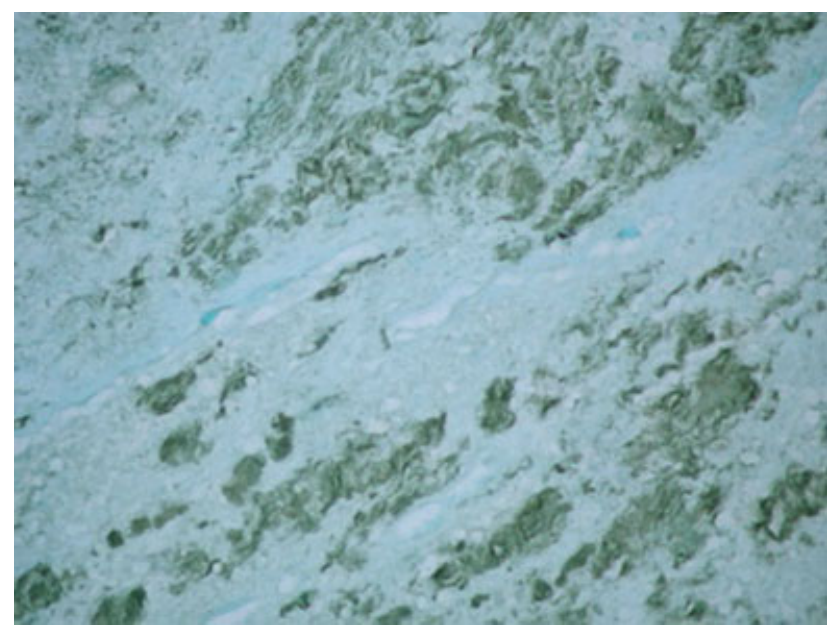

Fig. 4 Base of tongue schwannoma showing positive cytoplasmic immunostaining for S-100 protein; diaminobenzidine (DAB) chromogen; Meyer hematoxylin counterstain x100.

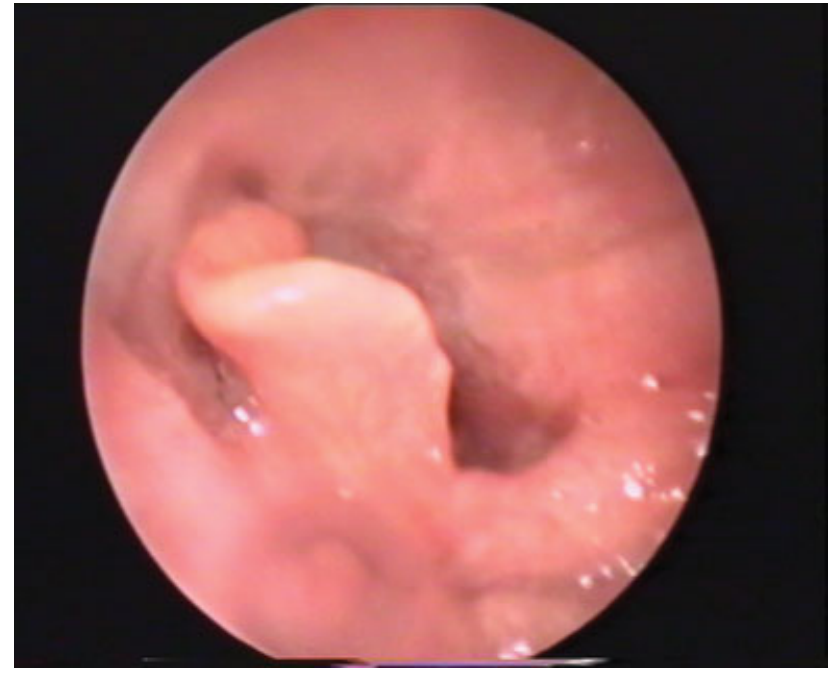

Fig. 5 Base of tongue schwannoma, 10 years postoperative.

(Antoni-A areas), in which the cells were closely arranged in short bundles and interlacing fascicles with their nuclei aligned in parallel rows, forming a palisading pattern, and the Verocay bodies. The hypocellular pattern (Antoni-B areas) showed hypocellularity with myxoid changes, and the cells were arranged haphazardly within a looselytextured matrix. Necrosis and mitotic figures were absent, and numerous blood vessels of varying sizes (with thick hyalinized walls) were present. The diagnosis was schwannoma of the BT; this was confirmed by immunohistochemical analysis, which revealed a strong expression of S-100 protein (-Figs. 3, 4).

The patient was followed-up regularly (every 3-6 months) for 40 months; and, accidentally, she came back after 10 years (for an unrelated reason) and showed no evidence of recurrence (-Fig. 5 ).

\section{Literature Search}

The authors searched the PubMed database and Google up to August 2018. The following search terms were applied: tongue and lingual, combined with schwannoma, or neurilemmoma. Titles and abstracts were screened, and then the full text (if available) was retrieved for review. Inclusion criteria included: English language, on humans, and, then, only (supraglottic; hypopharyngeal) tongue base masses were considered. All other articles were excluded.

After screening, 17 articles were included in this review, reporting 20 cases total. We could not collect one article's full data. ${ }^{16}$ The age of presentation ranged from 9 to 75 years, affecting predominantly females (12 cases); our case was a female patient. Dysphagia and lump sensations were the most common presenting symptoms. Other data are reported in - Table 1.

\section{Discussion}

The differential diagnosis of BT masses should include: lingual thyroid, hemangioma, lipoma, lymphangioma, benign salivary gland tumors, leiomyoma, along with neurofibroma and 
Table 1 Demographics and treatment data of 15 patients with base of tongue schwannomas reported in the literature

\begin{tabular}{|c|c|c|c|c|c|c|}
\hline Paper & Year & Gender & Age & Size $(\mathrm{cm})$ & Presentation & Surgical approach \\
\hline Dreher et al ${ }^{14}$ & 1997 & $\mathrm{~F}$ & 31 & 3 & Dysphagia & Transoral \\
\hline Spandow et al ${ }^{16}$ & 1999 & - & - & - & - & - \\
\hline de Bree et $\mathrm{al}^{13}$ & 2000 & $\mathrm{~F}$ & 24 & 5 & Lump & Submandibular \\
\hline Nakasato et al ${ }^{17}$ & 2005 & $\mathrm{~F}$ & 9 & 2 & Sore throat & \\
\hline Lump & Transoral & & & & & \\
\hline $\begin{array}{l}\text { Lopez-Jornet and } \\
\text { Bermejo-Fenoll }\end{array}$ & 2005 & $\mathrm{M}$ & 39 & 0.8 & Lump & Transoral \\
\hline \multirow[t]{3}{*}{ Hsu et al ${ }^{8}$} & 2006 & $M$ & 20 & 5 & Bleeding & Transoral \\
\hline & & $\mathrm{F}$ & 39 & 4 & Dysphagia & Trans-hyoid \\
\hline & & $\mathrm{F}$ & 32 & 1.8 & Lump & Transoral \\
\hline Ying et al ${ }^{19}$ & 2006 & $\mathrm{~F}$ & 26 & 4 & Dysphagia & Transoral \\
\hline \multirow[t]{2}{*}{ Batra et al ${ }^{20}$} & 2007 & $M$ & 30 & 3 & Dysphagia; abscess & Transoral \\
\hline & & $\mathrm{M}$ & 33 & 3 & Dysphonia & Transoral \\
\hline Ballesteros et $\mathrm{al}^{21}$ & 2007 & $\mathrm{~F}$ & 31 & 2 & Local Pain & $\mathrm{CO}_{2}$-Transoral \\
\hline Sawhney et $\mathrm{al}^{4}$ & 2008 & $\mathrm{~F}$ & 37 & 4.6 & Dysphagia, snoring & Submandibular \\
\hline Monga et $\mathrm{al}^{22}$ & 2013 & $M$ & 20 & 2 & Lump & Transoral \\
\hline Jayaraman et a ${ }^{23}$ & 2013 & $\mathrm{~F}$ & 25 & 3 & Lump & Transoral \\
\hline George et $\mathrm{al}^{12}$ & 2014 & $M$ & 26 & 4 & Lump, dysphonia & $\begin{array}{l}\text { Left paramedian lip spitting } \\
\text { approach with mandibulotomy } \\
\text { and mandibular swing }\end{array}$ \\
\hline Kamath et $\mathrm{al}^{25}$ & 2014 & $\mathrm{~F}$ & 50 & 2 & Throat discomfort & Transoral \\
\hline Roy et $\mathrm{al}^{27}$ & 2015 & $\mathrm{M}$ & 75 & 3 & Dysphagia, lump & Transoral \\
\hline Badar et a $\left.\right|^{28}$ & 2016 & $\mathrm{~F}$ & 24 & - & Pressure & Transoral \\
\hline Sharma and Rai ${ }^{29}$ & 2016 & $\mathrm{~F}$ & 20 & $4 \times 4$ & Dysarthria, dysphagia & Transoral \\
\hline
\end{tabular}

schwannoma. Although schwannomas are among the most common neoplasms found in the parapharyngeal space, intrapharyngeal occurrence of this kind of tumor is very rare. The posterior pharyngeal wall was previously reported to be the site of origin in a few reports. ${ }^{6}$ The etiology of schwannoma is not clear, and it is suggested to be derived from the nerve sheath Schwann cells, which surround the cranial, peripheral, and autonomic nerves. ${ }^{5-11}$

Schwannomas of BT show very slow growth; thus, a long time would pass before presentation. The lesion shows no age, no racial or gender predilection (although a female predominance could be noticed). The common presentations are a painless lump of the tongue, deglutition disorders, pain (or discomfort) and dysphonia (-Table $\mathbf{1}$ ).

The symptoms of schwannoma are non-specific and might depend its the size and location. Radiological examinations (sonography, CT and magnetic resonance imaging [MRI]) might be helpful for estimation of the tumor size, site, margins, and infiltrations of the surrounding structures. ${ }^{28}$ However, microscopic examination is a cornerstone to confirm diagnosis. Characteristic signs are the palisading of the spindle-shaped Schwann cells around the central acellular area (called Verocay bodies). ${ }^{4,12-20}$
A complete surgical excision with preservation of the nerve is the accepted treatment option for a BT schwannoma. The transoral approach is the most common route used in resecting those masses. ${ }^{9}$ Other open approaches have been reported. Carbon dioxide laser excision has also been applied to treat schwannomas of the $\mathrm{BT}^{4,9,11-13,21}$

Carbon dioxide laser has a wavelength of $10,600 \mathrm{~nm}$, which is strongly absorbed by water, resulting in cutting by tissue vaporization. ${ }^{10}$ The beam also has a sharp and a very precise effect with little injury to adjacent tissue at the surgical margins. It provides a clear, relatively dry field during dissection via sealing small blood vessels (less than $0.5 \mathrm{~mm}$ diameter). The beam has short wavelengths $(0.3 \mathrm{~mm})$ that would not allow deep tissue penetration; hence, no tissue damage, high organ/neurovascular preservation, smooth postoperative period, and less complication; however, availability of the machine, high costs and inadequate training of surgeons might limit this technique. ${ }^{9,10}$ Other investigators suggested the open techniques, such as the submandibular or the paramedian lip-splitting approach, with mandibulotomy and mandibular swing, if a mass is encountered at the posterolateral BT and has a size $>4.0 \mathrm{~cm} .{ }^{4,12,13}$ Although open approaches might give better exposure, they present higher 
risk of damaging the neurovascular bundle, with significant morbidity. ${ }^{20}$ Obviously, surgical resection of BT schwannomas has its inherent difficulties due to the natural hidden area with complex neurovascular anatomy, which might cause significant morbidities, such as dysphagia, aspiration, and dysarthria. Operative care stresses upon neurovascular preservation along with airway management and other anesthetic problems. ${ }^{24}$

In this paper, we present the case of a pedunculated hypopharyngeal/supraglottic BT schwannoma that was completely excised via the transoral approach with a $\mathrm{CO}_{2}$ laser (the patient in tonsillectomy position). After histopathological examination and immunohistochemistry, the schwannoma was documented. Only three reports mentioning this method of surgical treatment could be found in the literature, in English language. ${ }^{5,10,11}$

Schwannomas do not report recurrence if they are completely removed. ${ }^{24}$ In contrast to multiple neurofibromatosis (von Recklinghausen disease), schwannomas almost never undergo malignant transformation. ${ }^{14}$ Because of lack of signs from the $9^{\text {th }}$ and $10^{\text {th }}$ cranial nerves postoperatively, it is suggested that the nerve of origin of the tumor is the peripharyngeal plexus. ${ }^{15}$

In a recent systematic review, all patients reported uneventful postoperative recoveries, with no postsurgical complications, such as nerve damage or loss of tongue function/sensation. The mean follow-up period range was 1.5 to 60 months (mean $=13$ months), with no evidence of recurrence in any of the cases. ${ }^{24}$ The current case reports a longer follow-up period (10 years).

The authors present this case to raise medical awareness about BT schwannoma; this type of tumor might be rare, does not recur after complete excision, and there have been no reports of malignant transformation. Immunohistochemistry precludes definitive diagnosis. We recommend that transoral $\mathrm{CO}_{2}$ laser should be added to the surgical armamentarium for the management of future similar cases. The area of the BT might represent a challenge for surgeons regarding difficulty of approach, operative complications and postoperative functional disabilities. With this kind of surgeries, open approach and flap reconstruction might be required for excising large lesions. This can be accepted with malignant lesions (in which oncological safety is the role), but not with benign lesions, in which the intervention must be carried on smoothly, without any functional disability and with the least morbidity possible. This requires skillful, precise and minimal tissue dissection, which can be accomplished by $\mathrm{CO}_{2}$ Laser (especially when coupled with a surgical microscope). In this way, $\mathrm{CO}_{2}$ laser might provide an effective management option for such lesions because of the easy access to the lesion. It might offer significant benefits in terms of bloodless surgery, postoperative morbidity, and the length of stay of the patient in hospital. The early and optimal surface reepithelization of the $\mathrm{CO}_{2}$ laser wound, with no need for flap reconstruction, represents the most important advantage over the conventional surgical wound.

The present study is not free of limitations. These might include the use of limited search database. Also, the study obeys the literature in reporting data, even with thorough extraction of available data.

\section{Final Comments}

Tongue base schwannomas are rare. Transoral complete excision of the tumor is the treatment of choice. Carbon dioxide laser surgery is a minimally invasive treatment option that has been performed in a few cases (including the current one) with excellent results. When coupled with a surgical microscope, the $\mathrm{CO}_{2}$ laser beam could reach difficult areas in the upper aerodigestive tract. The advantages might include meticulous dissection, minimal bleeding, less morbidity and good functional outcome. After complete resection, recurrence is rare and the malignant transformation is extremely rare.

Conflicts of Interest

The authors declare that there are no conflicts of interest.

\section{References}

1 Kapadia SB. Tumors of the nervous system. In: Barnis L, ed. Surgical Pathology of the Head and Neck. Vol. 2, 2nd ed. NewYork, NY: Marcel Dekker Inc; 2000:795-798

2 Gooder P, Farrington T. Extracranial neurilemmomata of the head and neck. J Laryngol Otol 1980;94(02):243-249

3 Jadwani S, Bansod S, Mishra B. Intraoral schwannoma in retromolar region. J Maxillofac Oral Surg 2012;11(04):491-494

4 Sawhney R, Carron MA, Mathog RH. Tongue base schwannoma: report, review, and unique surgical approach. Am J Otolaryngol 2008;29(02):119-122

5 Chandra M, Singh P, Venkatchalam VP. Tongue Schwannoma: A case report with review of literature. JK Pract 2013;18(1-2): 28-34

6 Huang CM, Leu YS. Schwannoma of the posterior pharyngeal wall. J Laryngol Otol 2002;116(09):740-741

7 Arda HN, Akdogan O, Arda N, Sarikaya Y. An unusual site for an intraoral schwannoma: A case report. Am J Otolaryngol 2003;24 (05):348-350

8 Hsu YC, Hwang CF, Hsu RF, Kuo FY, Chien CY. Schwannoma (neurilemmoma) of the tongue. Acta Otolaryngol 2006;126(08): 861-865

9 Lira RB, Gonçalves Filho J, Carvalho GB, Pinto CA, Kowalski LP. Lingual schwannoma: case report and review of the literature. Acta Otorhinolaryngol Ital 2013;33(02):137-140

10 Mehrzad H, Persaud R, Papadimitriou N, Kaniyur S, Mochloulis G. Schwannoma of tongue base treated with transoral carbon dioxide laser. Lasers Med Sci 2006;21(04):235-237

11 Cohen M, Wang MB. Schwannoma of the tongue: two case reports and review of the literature. Eur Arch Otorhinolaryngol 2009;266 (11):1823-1829

12 George NA, Wagh M, Balagopal PG, Gupta S, Sukumaran R, Sebastian P. Schwannoma base tongue: Case report and review of literature. Gulf J Oncolog 2014;1(16):94-100

13 de Bree R, Westerveld GJ, Smeele LE. Submandibular approach for excision of a large schwannoma in the base of the tongue. Eur Arch Otorhinolaryngol 2000;257(05):283-286

14 Dreher A, Gutmann R, Grevers G. [Extracranial schwannoma of the ENT region. Review of the literature with a case report of benign schwannoma of the base of the tongue]. HNO 1997;45 (06):468-471

15 Triaridis C, Tsalighopoulos MG, Kouloulas A, Vartholomeos A. Posterior pharyngeal wall schwannoma (case report). J Laryngol Otol 1987;101(07):749-752 
16 Spandow O, Fagerlund M, Bergmark L, Boquist L. Clinical and histopathological features of a large parapharyngeal neurilemmoma located at the base of the tongue. ORL J Otorhinolaryngol Relat Spec 1999;61(01):25-30

17 Nakasato T, Kamada Y, Ehara S, Miura Y. Multilobular neurilemmoma of the tongue in a child. AJNR Am J Neuroradiol 2005;26 (02):421-423

18 López-Jornet P, Bermejo-Fenoll A. Neurilemmoma of the tongue. Oral Oncology Extra 2005;41(07):154-157

19 Ying YL, Zimmer LA, Myers EN. Base of tongue schwannoma: a case report. Laryngoscope 2006;116(07):1284-1287

20 Batra K, Rai AK, Chaudhary N, Topno S. Two cases of neurilemmoma of the tongue. Ear Nose Throat J 2007;86(11):679-681

21 Ballesteros F, Vilaseca I, Blanch JL, Gaspa A, Bernal-Sprekelsen M. Base of tongue neurilemmoma: excision by transoral laser microsurgery. Acta Otolaryngol 2007;127(09):1005-1007

22 Monga S, Malik JN, Sharma AP. Schwannoma tongue. JCR 2013http://dx.doi.org/10.17659/01.2013.0052

23 Jayaraman V, Balasubramanian B, Senthivelu R. Schwannoma of the tongue-a rare clinical entity. IJDSR 2013;1(03):53-55
24 Sitenga JL, Aird GA, Nguyen A, Vaudreuil A, Huerter C. Clinical features and surgical treatment of schwannoma affecting the base of the tongue: A systematic review. Int Arch Otorhinolaryngol 2017;21(04):408-413

25 Kamath MP, Kini H, Shenoy SV, Deviprasad D, Prakash N, Pai R. Schwannoma of the base of tongue - A rare presentation. Egyptian J Ear Nose Throat Allied Sci 2014;15:61-64

26 Villarreal Renedo PM, Monje Gil F, Junquera Gutiérrez LM, De Vicente Rodríguez JC, Morillo Sánchez AJ. Treatment of oral and oropharyngeal epidermoid carcinomas by means of CO2 laser. [Article in English, Spanish]. Med Oral 2004;9(02):172-5, 168-72

27 Roy P, Chakraborty S, Das S, Roy A. Solitary Neurofibroma at the Base of the Tongue: A Rare Presentation. Indian J Dermatol 2015; 60(05):497-499. Doi: 10.4103/0019-5154.16437

28 Badar Z, Farooq Z, Zaccarini D, Ezhapilli SR. Tongue base schwannoma: differential diagnosis and imaging features with a case presentation. Radiol Case Rep 2016;11(04):336-340

29 Sharma S, Rai G. Schwannoma (Neurilemmoma) on the Base of the Tongue: A Rare Clinical Case. Am J Case Rep 2016;17(17): 203-206 